\title{
Academic support of the process for preparing students for intercultural interaction in the context of the subject- language integrated environment
}

\author{
Nelly Savelyeva ${ }^{1}$, Yelena Gnatyshyna ${ }^{2}$, Natalie Nevrayeva ${ }^{1}$, Yekaterina Bozhko $^{1}$, Svetlana Surovtseva ${ }^{3}$, and Irina \\ Salimova $^{3}$ \\ ${ }^{1}$ Ural Federal University named after the first President of Russia B. N. Yeltsin, Dept. of Foreign Languages and Translation, \\ 620002 Ekaterinburg, Russia \\ ${ }^{2}$ South-Ural State Humanitarian Pedagogical University, Vocational Pedagogical Institute, 454080 Chelyabinsk, Russia \\ ${ }^{3}$ South-Ural State Humanitarian Pedagogical University, Dept. of Foreign Languages, 454080 Chelyabinsk, Russia
}

\begin{abstract}
The issue of preparing non-linguistic faculty students for intercultural interaction in the context of the subject-language integrated environment is quite a topical one, and theory and practice of higher education have accumulated considerable experience in this process. However, we have to admit that in modern pedagogical science no research has been so far dedicated either to the development of effective and logical system of preparing non-linguistic faculty students for intercultural interaction, or to the identification of optimal conditions for the functioning of such system. The statements above convinced us in the need to develop the respective proprietary system and pedagogical conditions, which would meet the peculiarities of the given age of students, of the requirements of the Federal State Education Standards of higher education, and of the requirements to the personality of the modern world reflected in national and international documents.
\end{abstract}

\section{Introduction}

The mechanism for identifying a set of pedagogical conditions for preparing students to intercultural interaction is conditioned by the social demand of the state and society related to the process of vocational training in higher education, as well as by peculiarities and contents of the process of intercultural interaction, and by the opportunities of activity and integrative approaches.

\section{Materials and methods}

Before proceeding to a detailed description of the essence of pedagogical conditions in the context of our research, let us define this concept. The term "condition" as a philosophical category expresses the relation of an object to the surrounding phenomena, without which it cannot exist [1, P. 112].

In modern academic and pedagogical research, the term "condition" is widely used when solving problems arising during the implementation of a holistic pedagogical process, which, in turn, makes up the essence of the "pedagogical conditions" concept.

Thus, V.I. Andreev, A.Ya. Nayn, N.M. Yakovleva define the concept of "pedagogical conditions" as a combination of any measures of pedagogic influence and opportunities offered by the material-spatial environment
[2; 3; 4]. N. V. Ippolitova, M. V. Zvereva and others define a pedagogical condition as a process of designing a pedagogical system, in which such conditions are one of the components [5]. In their turn, B. V. Kupriyanov and S. A. Dynina define pedagogical conditions as the systematic work on specification of the consistent patterns as stable links of the educational process, providing the possibility to verify the results of academic and pedagogical research [6].

The analysis of numerous academic and pedagogical studies allows us to conclude that there are various classifications of pedagogical conditions in modern pedagogical science [5]:

1. organizational and pedagogical conditions (V.A. Belikov, S.I. Kozyreva, S.N. Pavlov, A.V. Sverchkov, etc.) are a set of purposefully designed opportunities of contents, forms and methods of the integral pedagogical process serving as a basis for managing the functioning and development of a procedural aspect of the pedagogical system;

2. psychological and pedagogical conditions (N.V. Zhuravskaya, A.V. Krugliy, A.V. Lysenko, A.O. Malykhin and others) are a set of purposefully designed interconnected and interdependent opportunities of the educational and material-spatial environment aimed at developing personal dimension of the pedagogical system;

3. didactic conditions (M.V. Rutkovskaya) are a result of purposeful selection, design, and application of

\footnotetext{
*Corresponding author: nellik1983@mail.ru
} 
elements of contents, methods and organizational teaching methods for achieving didactic goals.

Based on the statements above, let us emphasize fundamental features of pedagogical conditions, which are important for consideration in the reasoning below:

- pedagogical conditions should have external influence and complement the system in a praxeological context;

- in accordance with the tasks set pedagogical conditions should have a positive impact on efficiency and effectiveness of the developed system;

- certain pedagogical conditions should meet the requirements of necessity (i.e. impossibility of reaching the planned outcomes without their use) and sufficiency (i.e. availability of stable positive changes in the newly formed innovation of the student's personality).

Thus, we will refer to pedagogical conditions as to a set of praxeological measures aimed at optimizing the functioning of the studied pedagogical phenomenon and the improving the controllability thereof in the context of a non-linguistic faculty of a university.

It is worth mentioning that the integrative approach determines the strategic basis for identifying pedagogical conditions taking into account the factors of interdisciplinary integration, whereas the activity approach contributes to the determination of their substantive and methodological contents from the point of view of involving a non-linguistic faculty student in an intercultural dialogue. A meaningful reason for determining the choice of pedagogical conditions was the consideration of specific principles for the system implementation.

So, following the given logic of our research, let us imagine pedagogical conditions as a set of theoretical, methodological, procedural and activity and processual and resource components of interdisciplinary integration, which allows us to conclude that they are essential.

So, when developing the pedagogical conditions of the proposed system, we also took into account the following grounds:

- trends of modern pedagogical science;

- social demand and legislative acts in higher education;

- principles of preparing non-linguistic faculty students for intercultural interaction;

- structural features of the phenomenon in question;

- consideration of standards and requirements of various contemporary job descriptions;

- actual opportunities of the contemporary educational space of higher educational institutions, representing the base of the research;

- essence and peculiarities of the subject-language integrated environment.

\section{Results and Discussion}

Taking into account the above provisions, let us describe the essence of the pedagogical conditions for preparing non-linguistic faculty students for intercultural interaction.
The first pedagogical condition is the activation of the potential of authentic materials for preparing nonlinguistic faculty students for intercultural interaction in the context of the subject-language integrated environment.

The given condition ensures the optimization of the process in question by enhancing the participation of non-linguistic faculty students in various types of intercultural-oriented educational activities and is primarily related to the improvement of the methodological basis of the process of foreign language learning, which involves the extensive use of original learning materials. Thus, the activation of the potential of authentic materials is a didactic pedagogical condition.

Considering the criteria of substantial authenticity of an educational text, Russian methodologists Ye.V. Nosonovich and G.P. Milrud identify a number of aspects of their authenticity, namely [7]:

1) culturological authenticity (the use of texts shaping ideas about the main features of life of the target language speakers in all areas of the language functioning);

2) informative authenticity (use of texts containing relevant and meaningful information corresponding to the age peculiarities of the students);

3) situational authenticity (creating a natural situation of communication, meeting the needs of native speakers, naturalness of discussing the stated topic);

4) authenticity of the national mentality (analysis and discussion of the appropriateness of using a particular phrase in a foreign language);

5) reactive authenticity (the text's ability to evoke an authentic emotional, mental, and verbal response in the learners);

6) design authenticity (compliance of the text in the textbook with the original in order to attract the students' attention, and to facilitate the understanding of the communicative task of the text);

7) authenticity of pre-text and post-text tasks (during extra-curricular time when working with various sources of information)

Analysis of the opportunities of an authentic educational text also requires consideration of their types, among which I.I. Khaleeva distinguishes the following types: didactically-oriented (texts prepared by native speakers specifically for methodological purposes), semi-authentic (authentic texts adapted to the learning objectives), quasi-authentic (texts that allow for certain abbreviations of proper names, if there are many, and of historical footnotes) and actually authentic texts [8, P. 156].

The logic of our research also includes consideration of the functions of authentic texts used in the preparation of non-linguistic faculty students for intercultural interaction. In this regard, we support O.F. Kirsanova [9], who distinguishes:

- function of expansion providing for the replenishment of students' intercultural and linguistic knowledge;

- function of the development of oral speech skills presented in various forms of reproducing the contents of 
the text on intercultural topics (such as the task to continue the story or to speak on certain issues raised in the text);

- function of the development of semantic perception of the text (for example, the task to retell the text in your own words).

Discussing the need to enhance the potential of authentic materials in the process of preparing nonlinguistic faculty students for intercultural interaction in the subject-language integrated environment, let us mention that modern scholars in pedagogy distinguish several types of reading: scanning and skimming, aimed at obtaining the necessary information and general impression about the text contents; and reading for details implying a complete understanding of the text [10].

In the logic of our research, viewing scanning sets the task for the students either to get a general idea of the contents of the text on intercultural subjects or to search for specific information. This task can be achieved by reading the headings, certain paragraphs or sentences. In turn, skimming implies that the students would understand at least $70 \%$ of the text, and the secondary information contained therein must be understood without distortion. This type of reading is the most common in the context of real intercultural communication and is carried out in the framework of authentic informative texts containing information reflecting the peculiarities of the daily routine, life and culture of the country of the language being studied. Skimming forms a number of skills, including the ability to determine the topic and contents of the text judging by the title, distinguishing the main ideas, establishing a logical sequence of basic facts of the text having been read.

Authentic literary texts are characterized by reading for detail aimed at a complete understanding of the contents for the subsequent critical rethinking. This type of reading is more time-consuming; the reader may stop and read certain text fragments far more than once. A complete understanding of the text contents implies an understanding of its lexical, grammatical and syntactic meanings.

At a non-linguistic faculty, reading is aimed at extracting general information from the texts being read and understanding their contents, since information processing and understanding its contents is an important factor in memorizing the language material. It is necessary to create a positive emotional background for the effective learning of the language material and, as a result, it is possible to improve motivation and intensity of the students' intellectual activity. After all, it is motivation that significantly influences the effectiveness of learning foreign languages [11].

We share the view that there are three main stages in working with any authentic material: - preparatory stage, actual work with the material, and the final stage. At the preparatory stage, students are being motivated to work with the material offered, personal experience is emphasized in the context of the subject-language integrated environment, and the contents of the text is predicted on the basis of headings and pictures. Setting an authentic communicative task will be an essential element of this stage (for example, "You have a birthday party with your friends at a café. Study the menu and make an order"). Other necessary components will be: removal of lexical and contextual difficulties by defining contents by title, text structure, and illustrations to the text; recognition of unknown vocabulary in the text followed by its actualization by translation and nontranslation methods, depending on the level of language proficiency, and subsequent prediction of the text contents according to unknown words. At the same time, it is recommended to disclose the topic of the text by teaching the majority of the words contained therein, which, in turn, will influence the students' motivation for reading.

The actual work with the authentic material implies reading the text, watching videos, listening to audios or their certain parts in order to solve a specific intercultural communicative task set at the preparatory stage. The object of control when reading, watching a video or listening to an audio recording is the level of understanding of the material offered, the control of understanding being related to both communicative tasks and the type of reading, watching, and listening.

Analysis of numerous academic and pedagogical studies has allowed us to make a conclusion that using authentic video materials creates favorable conditions for the students to learn new information on country study, enables the students' getting acquainted with the life of people and their culture. This results in the emergence of "participation effect" contributing to the increased interest of students to the studied material, which undoubtedly influences the level and emotional coloring of their oral speech. In addition, this is the way to make the lessons as close as possible to the natural conditions of intercultural interaction, thus contributing to incidental memorization.

It is worth mentioning that although they may be inferior to the texts in terms of the volume of country study material, the effect of using authentic video materials is always higher than that of using texts,. The use of video materials significantly increases motivation and intensity of preparing students for intercultural interaction, develops listening skills, and allows increasing volume and level of educational material within the time of the lessons [12].

Summarizing the above, let us note that the context of the subject-language integrated environment in the conditions of contemporary society provides for a wide use of authentic materials by the subjects of the system and determines the variable ways of their effective interaction. The emphasis on the potential of authentic materials contributes to the intensification of intercultural-oriented activities of non-linguistic faculty students, and also has a systematic positive effect on the readiness of non-linguistic faculty students for intercultural interaction.

The second pedagogical condition is the intercultural facilitation of the process of preparing nonlinguistic faculty students for intercultural interaction.

The said pedagogical condition reflects the interpersonal factor of the subject-language integrated 
environment and acts as a psychological and pedagogical condition. The implementation of this condition is aimed at stimulating intercultural motives, and at developing the qualities of effective intercultural interaction (tolerance, intercultural empathy, communication skills).

The English word facilitation - means relief, help. The term "facilitation" is associated with the name of the psychologist and humanist C. Rogers, and is considered in pedagogy as a process that stimulates, initiates, and has a positive influence on a person, maintaining their need to be active through a special style of interaction. In accordance with C. Rogers, the main facilitation conditions are congruence, trust and empathic listening. Congruence is expressed in the teacher's ability to be sincere, which for them means to be a meaningful personality in relation to their students. Trust is manifested in the recognition of the student's value of as a person who deserves trust. Empathic listening is an inner understanding of the student's response to something.

Using the theory by C. Rogers, Russian researchers (E.N. Gusinsky, E.F. Zeer, L.N. Kulikova, A.B. Orlov, V.N. Smirnov, etc.), define facilitative pedagogical interaction as a subject to subject interaction involving, where personal growth both the teacher and the student.

According to business coaches, facilitation is aimed at making interaction within the group easier. This is both a process and a group of skills that allow one to effectively organize a discussion of a complex problem or a controversial situation without wasting time and to ensure that the outcome that satisfies a certain group will be achieved in a short time [13].

Facilitation technologies, which provide for the availability of special skills for conducting group processes, have relatively recently become the realities of Russian pedagogical science. Nowadays it has become obvious that the highly professional management of group educational processes (such as seminars, training sessions, meetings, negotiations, etc.) is based on a single core in the form of general technologies for effective interaction with the group and designing its working process. The use of these technologies will allow the teacher-facilitator to ensure maximum efficiency in conducting group processes and will help student groups in achieving the desired outcome of any complexity.

The concept of facilitation is determined by the requirements for facilitators, which include:

- deep understanding and knowledge of the structure of the learning process, its material and technical support, and generally accepted values;

- analytical, fact-based, systematic approach to the educational process and good methodological abilities;

- actual ability for effective intercultural interaction;

- developed communication skills and listening skills;

- ability to set problems and be flexible in solving them, etc. [14].

Based on the point of view of psychologists [15], which distinguish three levels in the management process, let us emphasize that in our research intercultural facilitation will be implemented at motivational, processual, cognitive and operationalactivity levels.

Thus, at the motivational and target level of managing foreign language cognitive activity of nonlinguistic faculty students, which is based on the facilitative-stimulating function of the didactic intercultural influence, the teacher and the learner are linked by mutual interest in the cognition process. At this stage we consider it expedient and necessary for a teacher to identify the potential of non-linguistic faculty students for determining their own intercultural influence, strategy and to select the most effective techniques of managing intercultural educational activities. The teacher offers problem tasks, where the motivational conditions contain the students' action program, and the choice and use of specific training tools is predetermined, which eventually results in the students' readiness to use the offered training tools in both reproductive and productive activities.

At the second processual-cognitive level, the teacher acts as a consultant, whereas the student becomes the subject of cognitive activity, reproduction and productivity. At this level, the learner carries out independent cognitive activity. At the same time, the teacher focuses on developmental counseling through cognitive and verbal activities, involving interaction and contact. At this stage it becomes advisable to use communicative problem tasks of intercultural themes, which contain no action program for the students, and there is no model for solving them. The algorithm of actions to solve such problems is independently developed by students, but with the guidance of a consulting teacher. The processual-cognitive level contributes to the readiness of a non-linguistic faculty student to find, select, extract, process language and speech tools required for solving a particular educational task.

At the third, operational-activity level of intercultural facilitation, which is based on self-management, the teacher offers assignments that require searching activity, full independence of student's thought and thinking with minimal management by the teacher as an expert. In this case, the managerial functions of the teacher are reduced, and the student implements selfmanagement [16].

Summarizing the above, let us mention that in our study intercultural facilitation should be considered as a trajectory of interpersonal cooperation with the students based on trust, sincerity, empathic listening providing for the learners' realization and personal acceptance of intercultural interaction foundations.

Thus, the successful implementation of this pedagogical condition ensures interpersonal interaction of the subjects of the given process inspired by intercultural dialogue, intensifying the development of intercultural motives of non-linguistic faculty students.

The third pedagogical condition is academic mobility in the preparation of non-linguistic faculty students for intercultural interaction.

This pedagogical condition reflects the contents and methodological factor of the subject-language integrated 
environment and plays an organizational and pedagogical role.

N.S. Brinev and R.A. Chuyanov understand academic mobility as a period of the student's study not in a country of citizenship. This period is limited in time and implies that the students will return to their country upon completion of their studies abroad [17].

V.I. Bogoslovskiy and S.A. Pisareva, in their turn, consider the fact of the academic mobility development in Russian universities as one of the most important areas of Russia's joining the Bologna process and introduction of a multi-level system to higher education [18, P. 4].

In accordance with the domestic law of the Russian Federation, international cooperation in the field of education sets the following goals defined in the Federal Law "On Education in the Russian Federation" dated December 29, 2012 [19]:

- to coordinate the interaction of the Russian Federation with foreign states and international organizations for the development of education;

- to improve international and domestic mechanisms for the development of education.

To achieve the above objectives, the same law provides for such areas of academic mobility as:

- development and implementation of educational programmes and academic programs in the field of education in cooperation with international or foreign organizations;

- sending students and pedagogical and academic staff of Russian organizations engaged in educational activities to foreign educational organizations ... for the purposes of training, advanced training, and improvement of academic and educational activities;

- participation in the activities of international organizations and in conducting international educational, research and scientific and academic and technical projects, congresses, symposia, conferences, seminars, or hosting these events independently, as well as bilateral and multilateral exchange of educational and academic literature.

We consider the involvement of the university in the process of international cooperation with foreign universities as the means of improving the quality of educational and academic work at the university implemented through participation in international educational and academic programmes. Introduction of modern programmes, active learning technologies, and research in those areas of knowledge, which are provided for by agreements with foreign universities, is a powerful stimulus for enhancing the effectiveness of work on preparing non-linguistic faculty students for intercultural interaction.

As a rule, international cooperation between Russian and foreign universities is implemented in the following areas: double degree programs; branches of foreign universities; joint research centers and educational programmes; MBA programs. The development of the students' academic mobility is determined by the support of such programs as ERASMUS+, NORTH2NORTH, MEVLANA, and is an important factor in the functioning of the international market for training highly qualified specialists [20].

Thus, the activity of a teacher engaged in the development of the students' academic mobility should be aimed at updating their individual experience based on a flexible analysis of their cognitive and professional interests, intentions, needs, and values. It becomes obvious that such kind of work requires that a teacher should not only reconsider their individual experience, but also take a fundamentally different approach to the educational programmes.

The academic mobility is one of the priority areas of international education, and the students' exchange education is the main pedagogical condition for its development. In this regard, we believe that the university academic mobility provides for:

1) the establishment of equal partnership of the university with foreign educational institutions;

2) the students' acquisition of additional subjectlanguage integrated knowledge;

3 ) the improvement of fluency in a foreign language;

4) the student's readiness for intercultural interaction ensuring integration into an international professional environment.

Summarizing the above, let us mention that the development of the university academic mobility contributes to the acquisition of intercultural knowledge and skills, the increase of the value of fluency in foreign languages, the strengthening of personal and professional international contacts, the stimulation of the students' interest to study the peculiarities of another country, its culture, traditions, etc.

\section{Conclusion}

Thus, the success of the functioning of the system for preparing non-linguistic faculty students for intercultural interaction in the context of a subject-language integrated environment depends on the arrangement of interdisciplinary integration, which includes theoreticalmethodological, procedural and activity and processual and resource components. Pedagogical conditions identified by us on the basis of the said components seem to be essential, since they ensure the formation of each of the elements of the studied innovation of the student's personality.

\section{References}

1. N.M. Borytko In the Space of Educative Activity: Monograph Acad. Ed. N.K. Sergeev 181 (Volgograd: Peremena, 2001).

2. V.I. Andreev V.I. Andreev. 3rd ed. - Kazan: Center for Innovative Technologies, Pedagogy: Educational Course for Creative Self-Development 608 (2012).

3. A.Y. Nayn A.Ya. Nayn Pedagogika. On the Methodologies of Dissertation Research 5, 44-49 (1995). 
4. N.M. Yakovleva Theory and Practice of Preparing Would-Be Teachers for Creative Solution of Educative Problems: Diss. Dr. of Ped. Sciences. Chelyabinsk, 403 (1992).

5. N.V. Ippolitova, N.A. Sterkhova Analysis of the "Pedagogical Conditions" Concept: Essence and Classification, GPE, 1, 8-14 (2012).

6. B.V. Kupriyanov Modern Approaches to the Definition of the Essence of the "Pedagogical Conditions" Category, BNKSU, 2, 101-104 (2001).

7. E.V. Nosonovich, G.P. Milrud Criteria of ContentRelated Authenticity of an Educational Text, FLS, 2 , 10-14 (2008).

8. I.I. Khaleeva Fundamentals of the Theory of Larning to Understand a Foreign Language / I.I. Khaleyeva. 267 (M.: Vysshaya Shkola, 2011).

9. O.F. Kirsanova, Use of Authentic Materials at the Lessons of English O.F. Kirsanova. 341 (M.: Prosveschenie, 2012).

10. M.A. Kazakova, Ye.A. Yevtyugina Authentic text materials by teaching foreign languages. Retrieved from: https://cyberleninka.ru/article/n/autentichnyetekstovye-materialy-v-obuchenii-inostrannomuyazyku (2019).

11. O.S. Makarova Social Motivation of Students in the Conditions of the Implementation of Feedback while Learning a Foreign Language Pedagogical Science and Practice - to the Region. Proceedings of the 16th Regional Research-to-Practice Conference. Stavropol State Pedagogical Institute, 185-191 (2016).

12. Ye.V. Revina Use of authentic video-materials in the process of teaching foreign languages. Retrieved from: https://cyberleninka.ru/article/n/ispolzovanie- autentichnyh-videomaterialov-v-protsesseobucheniya-inostrannomu-yazyku (2019).

13. Ars Vitae Development of facilitation skills. Retrieved from:

http://www.arsvitae.ru/articles/182/107/obuchenietrenerov.html (2019).

14. A.N. Popov, A.N. Kovalenko PPMBPPCS, Facilitation and its Role in Culture-Building Management of a Sports Organization, 12, 2, 137145 (2017).

15. A.B. Orlov Person-Centered Approach in Psychology, Psychotherapy, Education and Politics. Retrieved from:

http://www.tpabg.rts/libragy/scipubl/ rogers100.html (2019).

16. N.S. Brinev, R.A. Chuyanov Academic Mobility of Students as a Factor in the Development of the Internationalization Process of in Education. Retrieved from:

http: // www.prof.msu.ru/publ/omsk2/o60/html (2019).

17. V.I. Bogoslovskiy Development of Academic Mobility in Multi-Level University Education: Methodological Recommendations for Teachers/ V.I. Bogoslovskiy, S.A. Pisareva, A.P. Tryapitsyna.95 (SPb.: Russian State Pedagogical University Publishing House, 2007).

18. N.A. Tsvetkova, G.O. Yarygin, O.V. Lopach Policy of international student academic mobility in the Russian Federation. Retrieved from: https://cyberleninka.ru/article/n/politikamezhdunarodnoy-akademicheskoy-mobilnostirossiyskoy-federatsii (2019).

19. V.N. Chistokhvalov PES, History of the Academic Mobility Development in the Countries of the “Bologna area", 9, 33-43 (2009). 